\title{
Antioxidative and Antimelanoma Effects of Various Tea Extracts via a Green Extraction Method
}

\author{
Yihui Chen, ${ }^{1}$ Jyun-Yin Huang, ${ }^{2}$ Yichi Lin, ${ }^{3}$ I-Fan Lin, ${ }^{4}$ Yi-Ru Lu, ${ }^{5}$ \\ Li-Heng Liu, ${ }^{6}$ and Hui-Min David Wang $\mathbb{D}^{2,7}$ \\ ${ }^{1}$ Institute of Postharvest Technology of Agricultural Products, College of Food Science, Fujian Agriculture and Forestry University, \\ Fuzhou, Fujian 350002, China \\ ${ }^{2}$ Graduate Institute of Biomedical Engineering, National Chung Hsing University, Taichung 402, Taiwan \\ ${ }^{3}$ Department of Biology, University of Texas at San Antonio, San Antonio, TX 78249, USA \\ ${ }^{4}$ Graduate Institute of Biotechnology, National Chung Hsing University, Taichung 402, Taiwan \\ ${ }^{5}$ Department of Biotechnology, National Chung Hsing University, Taichung 402, Taiwan \\ ${ }^{6}$ Department of Life Science, National Chung Hsing University, Taichung 402, Taiwan \\ ${ }^{7}$ Center for Stem Cell Research, Kaohsiung Medical University, Kaohsiung 807, Taiwan
}

Correspondence should be addressed to Hui-Min David Wang; davidw@dragon.nchu.edu.tw

Received 7 July 2017; Revised 23 October 2017; Accepted 27 November 2017; Published 13 February 2018

Academic Editor: José A. Beltrán

Copyright (C) 2018 Yihui Chen et al. This is an open access article distributed under the Creative Commons Attribution License, which permits unrestricted use, distribution, and reproduction in any medium, provided the original work is properly cited.

Tea (Camellia sinensis) contains high level of antioxidant elements and is a well-known beverage consumed worldwide. The purpose of this study is to compare different concentrations of green tea, black tea, oolong tea 861, oolong tea 732, and jasmine green tea. These five types of tea extracts were known to have antioxidative properties, reducing power, and metal ion chelating activity. The current study compared these five extracts in terms of their inhibiting effects on human malignant melanoma: A2058 and A375. To determine the cell viability between normal cell and malignant melanoma cells, an MTT assay was applied to evaluate the cytotoxic potential on human melanoma cells, with all tea extracts showing decreased cell viability with increasing tea extract concentrations. Cytotoxicity on HaCat (normal skin cells) showed no effect on the cell viabilities at lower concentrations of the tea extracts. These results suggest the antioxidative effect of five tea extracts that protect against oxidation and melanoma production, with green tea and jasmine green tea showing the lowest cell viability when tested against malignant melanoma cells.

\section{Introduction}

Antioxidative compounds derived from natural plant species may help keep human skin at a physiologically healthy state by decreasing oxidative stress [1]. By reducing oxidative stress from reactive oxygen species (ROS), antioxidative compounds can prevent ROS-induced skin damage [2]. Oxidation produces free radicals that may lead to chain reactions, which can potentially lead to cell damage. To detect the free radical scavenging ability of antioxidants, 1,1-diphenyl-2picrylhydrazyl (DPPH) is commonly used [3]. Different types of tea extracts were produced to investigate their respective antioxidant activity. Chelating capacity involves a central metal ion attached to a large molecule, which is a ligand, and forms a ring structure. The ferric reducing potential assay is another way to analyze antioxidative properties, which involves the quantification of the reducing ability of antioxidants in reaction with a 2,4,5-tripyridyl-S-triazine $\mathrm{Fe}(\mathrm{III})$ (TPTZ) complex that forms a ferrous Fe(II)-TPTZ complex with a dark blue color [4]. A2058 is a highly invasive cell line from a 43-year-old male patient with malignant melanoma. A375 is cell line from a 54-year-old female patient with malignant melanoma. $\mathrm{HaCaT}$ cells are immortalized human keratinocytes, which are used for the study of epidermal homeostasis [5].

Melanoma typically starts from melanocytes, which are the cells that produce melanin. Melanoma often originates from melanocytes within moles on the skin during early stages. However, when treatments are ineffective and melanoma cells spread rapidly, metastatic melanoma occurs. 
The ultraviolet (UV) rays are one of the known causes of melanoma [6]. Our skin has the ability to protect us from exterior factors, controls body temperature, and stores water and fat. However, skin cancer happens during extended exposure of sunlight, leading to cancerous benign or malignant tumors, which is now a major cause of death among patients [7].

Tea is a well-known beverage across the world. Tea polyphenols, which are antioxidative, includes epigallocatechin (EGC), epicatechin (EC), epigallocatechin gallate (EGCG), and epicatechin gallate (ECG). EGCG is the most abundant catechin within a tea leaf, which accounts for $30 \%$ of the total polyphenol in dried leaves of green tea, from subjected to steaming or pan frying to inactivate endogenous polyphenol oxidase (PPO) [8]. Green tea normally has higher antioxidant potential than oolong tea or black tea, due to its high EGCG and EGC content. Black tea also has antioxidant properties, with the ability to scavenge free radical, inhibit lipid peroxidation, and chelate metal ions [9]. Gallic acid is one of the key components of black tea, with the ability to counter cancer cells through its cytotoxic activity [10]. Oolong tea, a semifermented 84 tea, contains high amount of tea polyphenols and strongest antioxidant activity [11]. Jasmine tea is a variation of green tea, with an extra step of jasmine flower scent transfer process, as compared to typical green tea. Jasmine tea can reduce the esophageal tumor burden, but epidemiological studies are lacking [12].

\section{Materials and Methods}

2.1. Chemicals and Reagents. Ascorbic acid (Vitamin C), ethylenediaminetetraacetic acid (EDTA), L-3,4-dihydroxyphenylalanine (L-DOPA), dimethyl sulfoxide (DMSO), 1,1diphenyl-2 picrylhydrazyl (DPPH), ethanol, ferrouschloride $\left(\mathrm{FeCl}_{2} \cdot 4 \mathrm{H}_{2} \mathrm{O}\right)$, ferric chloride $\left(\mathrm{FeCl}_{3}\right)$, kojic acid, methanol, potassium ferricyanide $\left(\mathrm{K}_{3} \mathrm{Fe}(\mathrm{CN})_{6}\right)$, 3-(4,5-dimethylthiazol-2-yl)-2,5-diphenyltetrazolium bromide (MTT), 3-tertbutyl-4-hydroxyanisole (BHA), and L-tyrosine were purchased from Sigma-Aldrich Company (St. Louis, MO, USA). Dulbecco's modified Eagle's medium (DMEM) and fetal bovine serum (FBS) were obtained from Gibco BRL (Gaithersburg, MD, USA).

2.2. Tea Extracts Process and Preparation. All five tea extracts were prepared with similar procedures. Green tea leaves were subject to panning at $280-300^{\circ} \mathrm{C}$ for $5-6 \mathrm{~min}$ [13]. Jasmine green tea leaves, black tea leaves, and oolong tea leaves were naturally dried indoors under ambient temperature (indoor wilting). Oolong tea leaves were then moved into a bamboo basket for tossing and turning to bruise the leaves. The leaves were repetitively rolled and dried by a CTC (cut, tear, curl) machine. The roasted oolong tea 732 was subject to an additional step of roasting at $100-120^{\circ} \mathrm{C}$ for 4 hours to produce a roasted flavor. Black tea was rolled by a CTC machine, which serves to bruise and damage the leaves, followed by oxidation of the tea polyphenols (tea fermentation) at $40^{\circ} \mathrm{C}$ for 2-3 hours. Final drying of all five tea leaves was at $80-120^{\circ} \mathrm{C}$. All five tea leaves were extracted with hot water at $85-95^{\circ} \mathrm{C}$, using 5 -liter hot water per $\mathrm{kg}$ of tea leaf, to produce a broth of 5\% solid content, which was filtered by using 10-micron PP filter bag. After vacuum concentration, the concentration was increased to $20 \% \mathrm{w} / \mathrm{v}$. Maltodextrin was added to achieve an extract: maltodextrin ratio of $2: 1$ (20\% tea soluble content, $10 \%$ maltodextrin w/v). The tea concentrates were then frozen at $-35^{\circ} \mathrm{C}$, followed by lyophilization for 72 hours $\left(0-50\right.$ hours at below $0^{\circ} \mathrm{C}, 50-72$ hours increasing to $45^{\circ} \mathrm{C}$ ) and pulverization to produce a fine tea extract powder.

\subsection{Assays of Antioxidant Effects}

2.3.1. DPPH Radical Scavenging Activity Assay. The DPPH assay is an antioxidant assay to monitor the free radical scavenging ability of antioxidants, where a stable free radial shows a deep violet color [14]. DPPH solution will change into bright yellow when it encounters a free radical scavenging compound. The $1,5,10,50$, and $100(\mu \mathrm{g} / \mathrm{ml})$ of the tea extract were added to the DPPH solution. The reaction of DPPH with an antioxidant releases a hydrogen, which leads to a decreased absorbance value at $517 \mathrm{~nm}$ and a bright yellow color, corresponding to a high DPPH scavenging ability. Vitamin C was used as positive control. The formula to calculate free radical scavenging activity is as in the following equation:

Scavenging activity $(\%)$

$$
=\frac{\left(\mathrm{OD}_{\text {control }}-\mathrm{OD}_{\text {sample }}\right)}{\mathrm{OD}_{\text {control }}} \times 100 \% \text {. }
$$

2.3.2. Metal Chelating Activity Assay. The chelating property of ferrous ion $\left(\mathrm{Fe}^{2+}\right)$ was tested. Different concentrations ranges of the tea samples were dissolved in DMSO, with the addition of $10 \mu \mathrm{L}$ solution of $\mathrm{FeCl}_{2} \cdot 4 \mathrm{H}_{2} \mathrm{O}(2 \mathrm{mM})$. Twenty $\mu \mathrm{L}$ of ferrozine was then added and the mixture blended for 10 minutes [15]. Upon reaction, the absorbance at $562 \mathrm{~nm}$ was monitored. EDTA was used as positive control. The formula to calculate metal chelating activity was similar to (1).

2.3.3. Reducing Power Assay. For assays of the reducing power ability of the extract, different concentrations ranges of each tea extract were mixed with $85 \mu \mathrm{L}$ of $67 \mathrm{mM}$ sodium phosphate buffer (pH 6.8) and $2.5 \mu \mathrm{L}$ of $20 \% \mathrm{~K}_{3} \mathrm{Fe}(\mathrm{CN})_{6}$ to investigate the reducing powers of the extracts. The mixture was kept at $50^{\circ} \mathrm{C}$ for $20 \mathrm{~min}$ and centrifuged for $10 \mathrm{~min}$ at $3,000 \mathrm{~g}$. The supernatant was then mixed with $2 \% \mathrm{FeCl}_{3}$ and the absorbance was measured at a wavelength of $700 \mathrm{~nm}$ with a BHA solution as positive control [7]. High absorbance values correspond to a high capacity for metal ion reduction.

2.4. Cell Line Cultures. Human melanoma cell lines were obtained from Bioresource Collection and Research Center (Taiwan): A2058 (BCRC number 60039), A375 (BCRC number 60263), HaCat (human skin keratinocytes) were cultured in Keratinocyte-SFM (Gibco, USA) supplemented with bovine pituitary extract and human recombinant epidermal growth factor [16]. 
TABLE 1: Five different concentrations with DPPH scavenging capacity of five tea extracts.

\begin{tabular}{|c|c|c|c|c|c|}
\hline \multicolumn{6}{|c|}{ DPPH scavenging capacity (\%) } \\
\hline Extracts $(\mu \mathrm{g} / \mathrm{ml})$ & 1 & 5 & 10 & 50 & 100 \\
\hline Maltodextrin & $\leq 5.00$ & $\leq 5.00$ & $\leq 5.00$ & $\leq 5.00$ & $\leq 5.00$ \\
\hline Green tea extract ${ }^{\mathrm{a}}$ & $56.12 \pm 0.93$ & $86.04 \pm 0.12$ & $84.87 \pm 6.49$ & $95.07 \pm 0.00$ & $94.81 \pm 0.57$ \\
\hline Black tea extract ${ }^{\mathrm{a}}$ & $52.83 \pm 3.53$ & $85.56 \pm 0.15$ & $84.74 \pm 2.47$ & $94.75 \pm 0.07$ & $94.62 \pm 0.21$ \\
\hline Oolong tea extract $861^{\mathrm{a}}$ & $52.85 \pm 2.47$ & $87.35 \pm 5.44$ & $91.83 \pm 0.28$ & $94.62 \pm 0.35$ & $93.51 \pm 1.84$ \\
\hline Oolong tea extract $732^{a}$ & $46.13 \pm 1.01$ & $42.67 \pm 3.30$ & $43.02 \pm 0.58$ & $74.60 \pm 0.28$ & $66.28 \pm 0.99$ \\
\hline Jasmine green tea extract $^{\mathrm{a}}$ & $55.43 \pm 1.80$ & $90.88 \pm 0.06$ & $82.36 \pm 6.10$ & $94.49 \pm 0.49$ & $94.68 \pm 0.00$ \\
\hline${\text { Vitamin } C^{\mathrm{b}}}$ & & & $80.82 \pm 0.00$ & & \\
\hline
\end{tabular}

${ }^{\mathrm{a}}$ Sample consists of $33 \%$ maltodextrin. ${ }^{\mathrm{b}}$ Vitamin $\mathrm{C}$ was used as a positive control on DPPH assay at $100 \mu \mathrm{M}$.

2.5. MTT Assay. The cell viability was determined with an MTT assay [17]. Cells were plated at a density of $8 \times$ $10^{3}$ cells/well in a 96-well plate and incubated for 24 hours before the additions of the 1,10 , and $50(\mu \mathrm{g} / \mathrm{ml})$ of the tea extracts, after which an MTT solution was added to each well. Culture medium was then discarded and DMSO added to each well. The absorbance of the formazan salt at $595 \mathrm{~nm}$ was measured, and cell viability was calculated as in the following equation:

$$
\text { Cell viability }(\%)=\frac{\mathrm{OD}_{\text {sample }}}{\mathrm{OD}_{\text {control }}} \times 100 \%
$$

\section{Results}

3.1. DPPH Free Radical Scavenging Activity Assay. The DPPH assay aims to detect free radical scavenging ability of antioxidants. The absorbance at $517 \mathrm{~nm}$ was monitored when the DPPH radical is neutralized, as the solution turns from blue violet to light yellow in color. Lighter color indicates better antioxidant ability. Table 1 illustrates the results for five different tea extracts, with Vitamin $\mathrm{C}$ as the positive control and maltodextrin as the negative control. In general, the higher the tea extract concentration, the higher the percentage of DPPH scavenging capacity. However, for all five tea extracts, $50 \mu \mathrm{g} / \mathrm{ml}$ tends to show higher or equivalent antioxidant ability than $100 \mu \mathrm{g} / \mathrm{ml}$. The comparison showed that green tea had the biggest radical scavenging effect. Oolong tea extract 861 is significantly more antioxidative than oolong tea extract 732 , which may be due to their difference in processing.

3.2. Metal Chelating Activity Assay. In an oxidative environment, ferrozine forms complexes with $\mathrm{Fe}^{2+}$. When the chelating materials are present, this complex construction is dislocated. When $\mathrm{Fe}^{2+}$ and ferrozine reacts together at $562 \mathrm{~nm}$, it reflects a higher chelating ability. Five different tea extracts had $\mathrm{Fe}^{2+}$ scavenging activities at a concentration range of $1-100 \mu \mathrm{g} / \mathrm{mL}$. Oolong tea extract had the highest value of $30 \pm 2.0$ at $100 \mu \mathrm{g} / \mathrm{mL}$. Jasmine green tea showed the highest chelating capacity of $18 \pm 0.03$ at $10 \mu \mathrm{g} / \mathrm{mL}$. Compared to the others, it has the lowest level of concentration needed to achieve a higher percentage of chelating capacity.

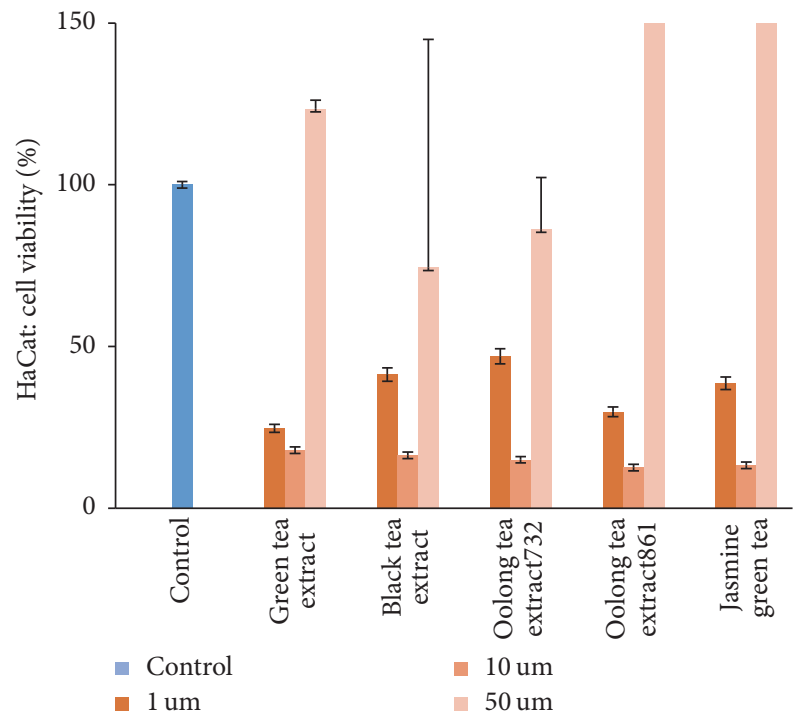

FIGURE 1: Effects of five extracts on cell viability of normal human cell and malignant melanoma cell according to MTT assay. Percentage of cell viability was measured in HaCat cultured with $1 \mu \mathrm{m}$, $10 \mu \mathrm{m}$, and $50 \mu \mathrm{m}$.

3.3. Reducing Power Assay. The ferrous ion chelating activity of tea extracts was investigated and shown in Table 3. During this assay, the reducing properties of the tea extracts were determined by monitoring their change in solution color, which turns from light yellow to blue violet when Fe(II)-TPTZ complex forms. Darker color represents better reducing power. Table 3 showed that the reducing power of black tea extract and oolong tea extract 861 was $2.83 \pm$ 0.51 at $50 \mu \mathrm{g} / \mathrm{mL}$ and $2.93 \pm 0.15$ at $50 \mu \mathrm{g} / \mathrm{mL}$, respectively. According to the results, the reducing power decreased as the concentration reaches $100 \mu \mathrm{g} / \mathrm{mL}$.

3.4. MTT Assay. The effect of the tea extracts on cell development was estimated with the MTT assay, which is a colorimetric assay for assessing cell viability. This assay is based on the dehydrogenase from the cell line that changes from light yellow color of MTT's tetrazolium into a blue color of MTT formazan. From Figure 1, it can be seen that, at a concentration of $1 \mu \mathrm{m}$ and $10 \mu \mathrm{m}$, the HaCat viability 


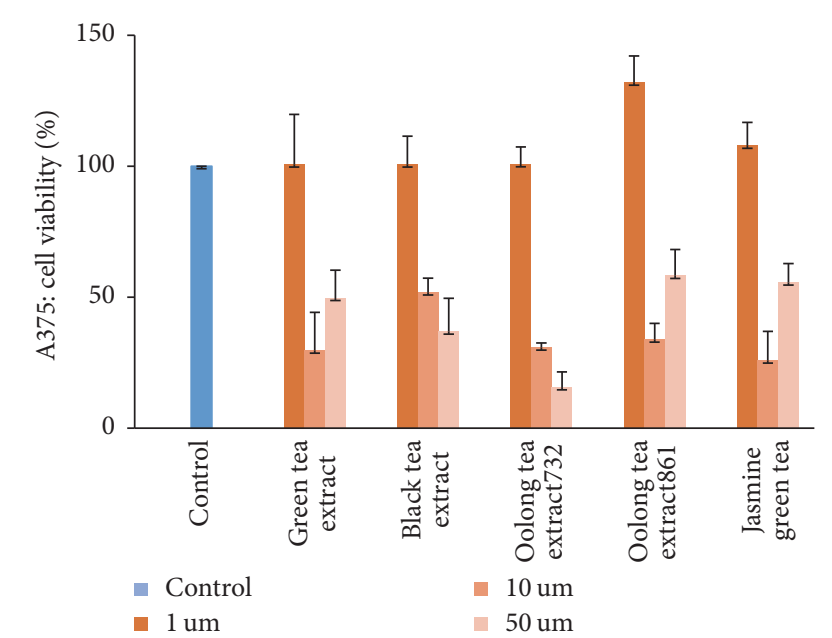

FIGURE 2: Effects of five extracts on cell viability of normal human cell and malignant melanoma cell according to MTT assay. Percentage of cell viability was measured in A2058 cultured with $1 \mu \mathrm{m}$, $10 \mu \mathrm{m}$, and $50 \mu \mathrm{m}$.

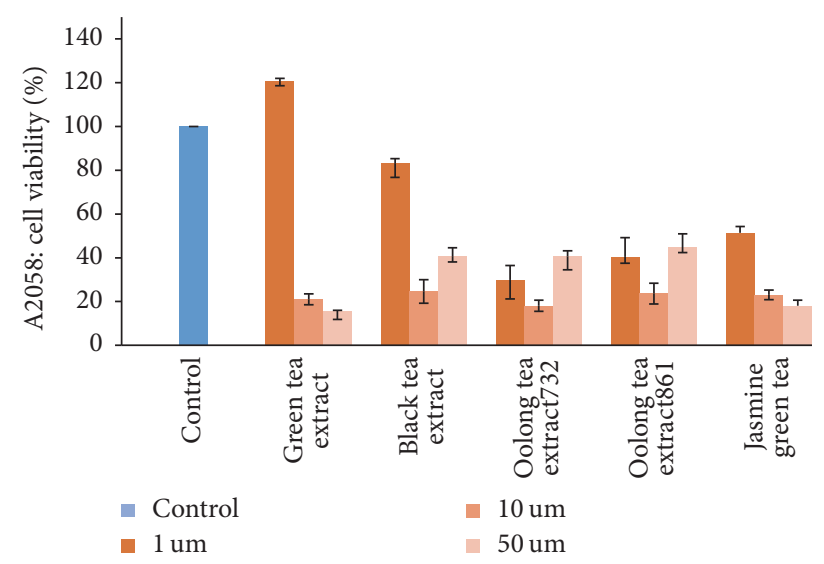

FigURE 3: Effects of five extracts on cell viability of normal human cell and malignant melanoma cell according to MTT assay. Percentage of cell viability was measured in A375 cultured with $1 \mu \mathrm{m}, 10 \mu \mathrm{m}$, and $50 \mu \mathrm{m}$.

showed the same pattern among the five tea extracts tested. As seen in Figure 2, the five tea extracts on A375 cell line show similar viability pattern as compared to that of the A2058 cell line in Figure 3, as both are malignant melanoma cells. The black tea extract and the oolong tea extract 732 on A375 show dose-dependent decrease in viability, while the green tea extract and the jasmine green tea extract show dosedependent decrease in A2058 cell viability.

\section{Discussion}

Tea is a popular traditional beverage and is known for its physiological functions such anticancer and antioxidative power. In this study, tea extracts made from the leaves of Camellia sinensis were analyzed; these were green tea, black tea, oolong tea, and jasmine green tea. The current study investigated the antioxidative effect of five different tea extracts by determining the DPPH scavenging capacity, chelating activity, and reducing power. The investigation determined the antioxidative power and included Vitamin $\mathrm{C}$ as the positive control and maltodextrin as the negative control, to compare with different types of tea at various concentrations. It was found that high concentrations of tea extracts had a profound impact on human cell. All five types of tea extracts showed an increased percentage of DPPH scavenging capacity and chelating activity. Oolong tea extract 732 was made with an additional high temperature roasting step, as compared to the oolong tea extract 861. Thermal processing may degrade catechins, which may be the cause of the lower DPPH scavenging capacity of oolong tea extract 732.

In this study, all tea extracts at a concentration of $50 \mu \mathrm{g} / \mathrm{mL}$ showed the highest capacity of scavenging DPPH (Table 1). In fact, tea polyphenols are represented as the main antioxidants in teas [18]. The five tea extracts were further analyzed by investigating their chelating activity. Oolong tea extract 861 had the highest chelating value $30 \pm 2.0$ at the highest concentration tested $(100 \mu \mathrm{g} / \mathrm{ml})$ (Table 2). However, all of the tea extracts showed the highest reducing power at $50 \mu \mathrm{g} / \mathrm{mL}$ (Table 3). This pattern was similar to the DPPH scavenging capacity as seen in Table $1[19,20]$.

Melanoma, a malignant tumor, begins in a specific type of skin cell and activates when the abnormal cells affect part of the body and proliferates uncontrollably [21]. The cytotoxic potential of the five tea extracts on two different melanoma cells (A2058 and A375) as well as on HaCat cells as a noncancerous cell line was also investigated [22] using the MTT assay. These cell lines were treated with various concentrations $(1,10$, and $50 \mu \mathrm{m})$ of the tea extracts for comparison. For HaCat cells, the five tea extracts at $50 \mu \mathrm{m}$ had minor effects, and all cellular viabilities exceeded $65 \%$ after a 24 -hour treatment. Thus, the tea extracts had no toxic effects on noncancerous human cells. Both A375 and A2058 are compromised, highly invasive melanoma cell lines [23]. All five tea extracts at $10 \mu \mathrm{m}$ and $50 \mu \mathrm{m}$ showed cytotoxic potential on both human melanoma cells tested. Nonthermal processing of tea may affect the bioactivity of the tea products, so the improvement in food quality may be achieved by adapting a green physical processing.

\section{Conclusion}

In summary, the experiments in this study demonstrated that the antioxidant activity was confirmed through DPPH free radical activity, chelating activity, and reducing power of the five tea extracts. Higher concentration of the tea extracts could potentially become a cancer treatment. The results suggested all five tea extracts investigated are promising natural antioxidants and potential antimelanoma agents, without toxicity against noncancerous human cells.

\section{Conflicts of Interest}

The authors have no conflicts of interest regarding the publication of this study. 
TABLE 2: Five different concentrations with chelating activity of five tea extracts.

\begin{tabular}{|c|c|c|c|c|c|}
\hline \multicolumn{6}{|c|}{ Chelating activity (\%) } \\
\hline Extracts $(\mu \mathrm{g} / \mathrm{ml})$ & 1 & 5 & 10 & 50 & 100 \\
\hline Maltodextrin & $\leq 5.00$ & $\leq 5.00$ & $59 \pm 0.01$ & $76 \pm 0.01$ & $79 \pm 0.00$ \\
\hline Green tea extract ${ }^{\mathrm{a}}$ & $\leq 10$ & $\leq 10$ & $\leq 10$ & $\leq 10$ & $14 \pm 1.0$ \\
\hline Black tea extract ${ }^{\mathrm{a}}$ & $\leq 10$ & $\leq 10$ & $20 \pm 0.03$ & $19 \pm 0.01$ & $25 \pm 3.0$ \\
\hline Oolong tea extract $861^{a}$ & $\leq 10$ & $\leq 10$ & $\leq 10$ & $19 \pm 0.01$ & $30 \pm 2.0$ \\
\hline Oolong tea extract $732^{a}$ & $\leq 10$ & $\leq 10$ & $\leq 10$ & $\leq 10$ & $27 \pm 1.0$ \\
\hline Jasmine green tea extract $\mathrm{t}^{\mathrm{a}}$ & $\leq 10$ & $\leq 10$ & $18 \pm 0.03$ & $\leq 10$ & $\leq 10$ \\
\hline EDTA $^{\text {b }}$ & & & $80.76 \pm$ & & \\
\hline
\end{tabular}

${ }^{\mathrm{a}}$ Sample consists of $33 \%$ maltodextrin. ${ }^{\mathrm{b}}$ EDTA was used as a positive control on metal chelating ability at $100 \mu \mathrm{M}$.

TABLE 3: Five different concentrations with reducing power of five tea extracts.

\begin{tabular}{|c|c|c|c|c|c|}
\hline \multicolumn{6}{|c|}{ Reducing power (OD 700) } \\
\hline Extracts $(\mu \mathrm{g} / \mathrm{ml})$ & 1 & 5 & 10 & 50 & 100 \\
\hline Maltodextrin & $\leq 5.00$ & $\leq 5.00$ & $\leq 5.00$ & $\leq 5.00$ & $\leq 5.00$ \\
\hline Green tea extract ${ }^{\mathrm{a}}$ & $0.35 \pm 0.02$ & $0.30 \pm 0.02$ & $0.25 \pm 0.01$ & $2.38 \pm 0.41$ & $2.046 \pm 0.17$ \\
\hline Black tea extract ${ }^{\mathrm{a}}$ & $0.26 \pm 0.04$ & $0.23 \pm 0.02$ & $0.23 \pm 0.02$ & $2.83 \pm 0.51$ & $2.71 \pm 0.24$ \\
\hline Oolong tea extract $861^{\mathrm{a}}$ & $0.29 \pm 0.06$ & $0.25 \pm 0.06$ & $0.36 \pm 0.02$ & $2.93 \pm 0.15$ & $2.44 \pm 0.20$ \\
\hline Oolong tea extract $732^{\mathrm{a}}$ & $0.19 \pm 0.00$ & $1.65 \pm 0.01$ & $0.23 \pm 0.01$ & $2.69 \pm 0.45$ & $2.60 \pm 0.24$ \\
\hline Jasmine green tea extract ${ }^{a}$ & $0.28 \pm 0.01$ & $0.32 \pm 0.03$ & $0.29 \pm 0.02$ & $2.73 \pm 0.57$ & $2.46 \pm 0.05$ \\
\hline $\mathrm{BHA}^{\mathrm{b}}$ & & & $0.56 \pm 0.03$ & & \\
\hline
\end{tabular}

${ }^{\mathrm{a}}$ Sample consists of $33 \%$ maltodextrin. ${ }^{\mathrm{b}} \mathrm{BHA}$ was used as a positive control on reducing power at $100 \mu \mathrm{M}$.

\section{Authors' Contributions}

Yihui Chen, Jyun-Yin Huang, Yichi Lin, I-Fan Lin, Yi$\mathrm{Ru}$ Lu, Li-Heng Liu, and Hui-Min David Wang conceived and designed the experiments; Yihui Chen performed the experiments and analyzed the data; I-Fan Lin contributed reagents, materials, and analysis tools; Jyun-Yin Huang, Yichi Lin, I-Fan Lin, Yi-Ru Lu, Li-Heng Liu, and Hui-Min David Wang wrote the paper. Yihui Chen and Jyun-Yin Huang contributed equally to this work.

\section{Acknowledgments}

This work was supported by grants from the Ministry of Science and Technology, Taiwan (MOST 104-2221-E-005-096MY2 and MOST 104-2628-E-005-004-MY3). The authors also thank the projects of Center for Stem Cell Research, Kaohsiung Medical University, Kaohsiung, Taiwan, KMUTP104G00, KMU-TP104G01, and KMU-TP104G02-05.

\section{References}

[1] H.-Y. Chou, C. Lee, J.-L. Pan et al., "Enriched astaxanthin extract from haematococcus pluvialis augments growth factor secretions to increase cell proliferation and induces MMP1 degradation to enhance collagen production in human dermal fibroblasts," International Journal of Molecular Sciences, vol. 17, no. 6, article 955, 2016.

[2] Y. C. Hseu, C. W. Chou, K. J. Senthil Kumar et al., "Ellagic acid protects human keratinocyte (HaCaT) cells against UVAinduced oxidative stress and apoptosis through the upregulation of the HO-1 and Nrf-2 antioxidant genes," Food and Chemical Toxicology, vol. 50, no. 5, pp. 1245-1255, 2012.
[3] D. Liu, Y. Deng, A. Gong, Y. Han, and H. M. Wang, "Impact of the Breakdown Behavior on Chinese Traditional Stewed Pork with Brown Sauce: Physical Properties Using Microstructural Analysis," Journal of Food Quality, vol. 2017, Article ID 4714919, 10 pages, 2017.

[4] S. Aydın and Y. Özdemir, "Development and characterization of carob flour based functional spread for increasing use as nutritious snack for children," Journal of Food Quality, vol. 2017, Article ID 5028150, 2017.

[5] K. J. Senthil Kumar, H.-L. Yang, Y.-C. Tsai et al., "Lucidone protects human skin keratinocytes against free radical-induced oxidative damage and inflammation through the up-regulation of $\mathrm{HO}-1 / \mathrm{Nrf} 2$ antioxidant genes and down-regulation of NF- $\kappa \mathrm{B}$ signaling pathway," Food and Chemical Toxicology, vol. 59, pp. 55-66, 2013.

[6] P.-H. Li, Y.-P. Chiu, C.-C. Shih et al., "Biofunctional Activities of Equisetum ramosissimum Extract: Protective Effects against Oxidation, Melanoma, and Melanogenesis," Oxidative Medicine and Cellular Longevity, vol. 2016, Article ID 2853543, 2016.

[7] H.-M. D. Wang, C.-Y. Chen, and P.-F. Wu, "Isophilippinolide a arrests cell cycle progression and induces apoptosis for anticancer inhibitory agents in human melanoma cells," Journal of Agricultural and Food Chemistry, vol. 62, no. 5, pp. 1057-1065, 2014.

[8] Y. C. Kim, S. Y. Choi, and E. Y. Park, "Anti-melanogenic effects of black, green, and white tea extracts on immortalized melanocytes," Journal of Veterinary Science, vol. 16, no. 2, pp. 135-143, 2015.

[9] W. C. Chan, E. Y. Soh, P. P. Tie, and Y. P. Law, "Antioxidant and Antibacterial Properties of Green, Black, and Herbal Teas of Camellia Sinensis," Pharmacognosy Reasearch, pp. 266-272, 2011. 
[10] C. D. Fernando and P. Soysa, "Extraction Kinetics of phytochemicals and antioxidant activity during black tea (Camellia sinensis L.) brewing," Nutrition Journal, vol. 14, no. 1, article no. 74, 2015.

[11] D. Kong, J. Wu, S. Sun, Y. Wang, and P. Xu, "A comparative study on antioxidant activity and inhibitory potential against key enzymes related to type 2 diabetes of four typical teas," Journal of Food and Nutrition Research, vol. 2, no. 9, pp. 652658, 2014.

[12] Y. Gao, N. Hu, X. Han et al., "Jasmine tea consumption and upper gastrointestinal cancer in China," Cancer Causes \& Control, vol. 20, no. 10, pp. 1997-2007, 2009.

[13] W. C. Chan, E. Y. Soh, P. P. Tie, and Y. P. Law, "Antioxidant and antibacterial properties of green, black and herbal teas of Camellia sinensis," 2011.

[14] C.-C. Lee, Y.-T. Chen, C.-C. Chiu, W.-T. Liao, Y.-C. Liu, and H.-M. David Wang, "Polygonum cuspidatum extracts as bioactive antioxidaion, anti-tyrosinase, immune stimulation and anticancer agents," Journal of Bioscience and Bioengineering, vol. 119, no. 4, pp. 464-469, 2015.

[15] C.-Y. Chen, C.-C. Chiu, C.-P. Wu, Y.-T. Chou, and H.-M. Wang, "Enhancements of skin cell proliferations and migrations via 6-dehydrogingerdione," Journal of Agricultural and Food Chemistry, vol. 61, no. 6, pp. 1349-1356, 2013.

[16] R. Preti, M. Rapa, and G. Vinci, "Effect of steaming and boiling on the antioxidant properties and biogenic amines content in green bean (Phaseolus vulgaris) varieties of different colours," Journal of Food Quality, vol. 2017, Article ID 5329070, 2017.

[17] P.-F. Wu, C.-C. Chiu, C.-Y. Chen, and H.-M. D. Wang, "7Hydroxydehydronuciferine induces human melanoma death via triggering autophagy and apoptosis," Experimental Dermatology, vol. 24, no. 12, pp. 930-935, 2015.

[18] Y.-C. Hseu, C.-C. Lee, Y.-C. Chen et al., "Antrodia salmonea in submerged culture exhibits antioxidant activities in vitro and protects human erythrocytes and low-density lipoproteins from oxidative modification," Food and Chemical Toxicology, vol. 66, pp. 150-157, 2014.

[19] E.-J. Lee and H.-D. Jang, "Antioxidant activity and protective effect on DNA strand scission of Rooibos tea (Aspalathus linearis)," BioFactors, vol. 21, no. 1-4, pp. 285-292, 2004.

[20] R. Fukasawa, A. Kanda, and S. Hara, "Anti-oxidative effects of rooibos tea extract on autoxidation and thermal oxidation of lipids," Journal of Oleo Science, vol. 58, no. 6, pp. 275-283, 2009.

[21] K. C. Cheng, M. C. Hsueh, H. C. Chang, A. Y. L. Lee, H. M. Wang, and C. Y. Chen, "Antioxidants from the Leaves of Cinnamomum kotoense," Natural Product Communications, vol. 5, no. 6, pp. 911-912, 2010.

[22] H. L. Yang, S. W. Lin, C. C. Lee et al., "Induction of Nrf2mediated genes by Antrodia salmonea inhibits ROS generation and inflammatory effects in lipopolysaccharidestimulated RAW264.7 macrophages," Food and Function, vol. 6, pp. 230241, 2015.

[23] B. H. Chen, H. W. Chang, H. M. Huang et al., "(-)-anonaine induces DNA damage and inhibits growth and migration of human lung carcinoma H1299 cells," Journal of Agricultural and Food Chemistry, vol. 59, no. 6, pp. 2284-2290, 2011. 


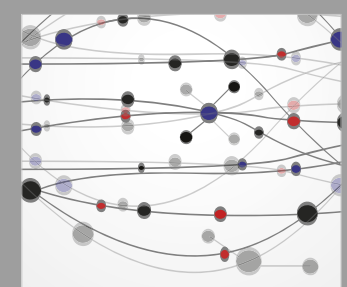

The Scientific World Journal
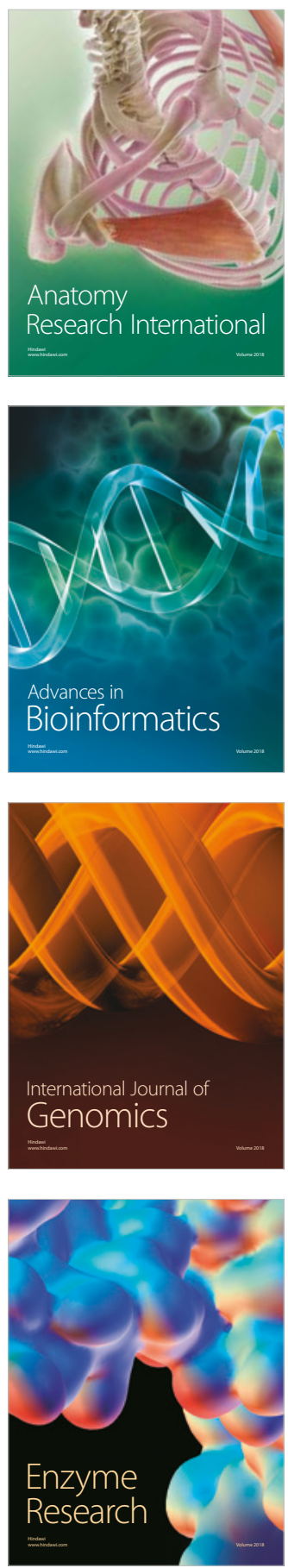
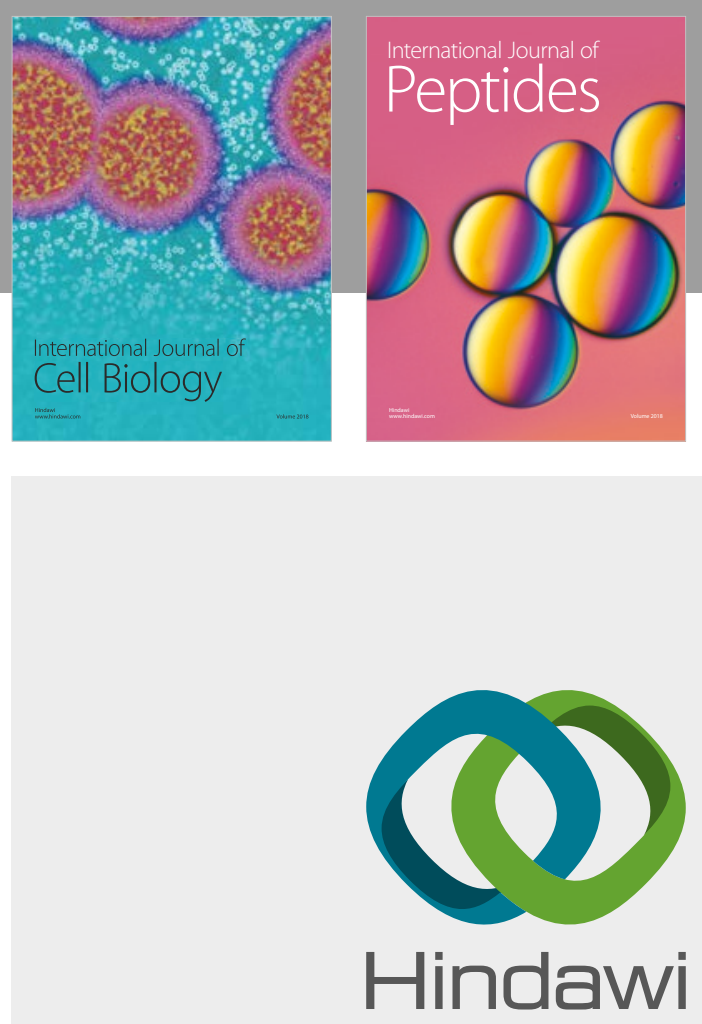

Submit your manuscripts at

www.hindawi.com
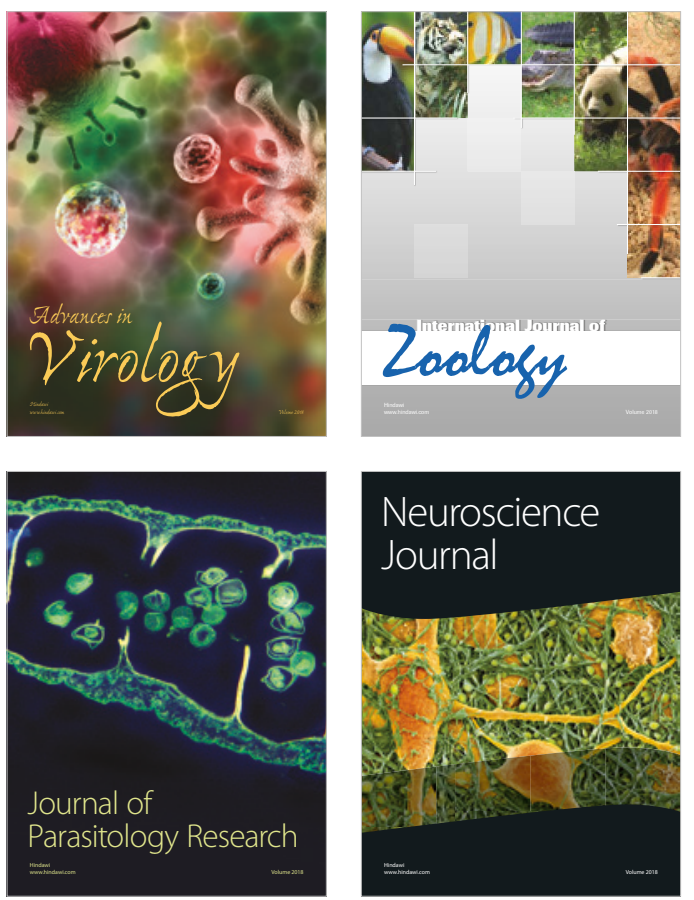
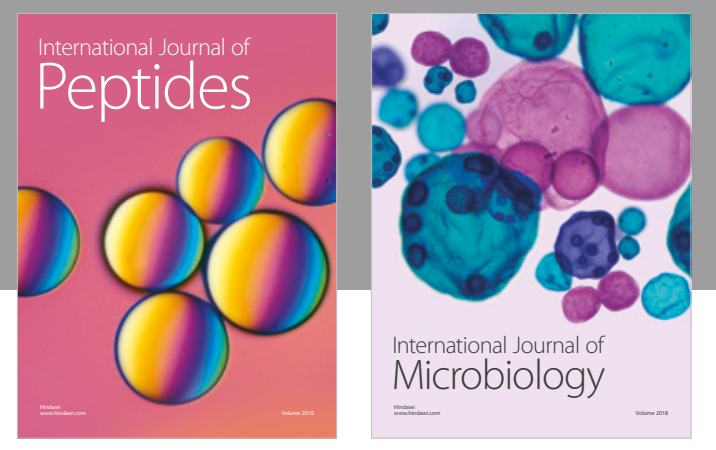

nternational Journal of Microbiology
Journal of
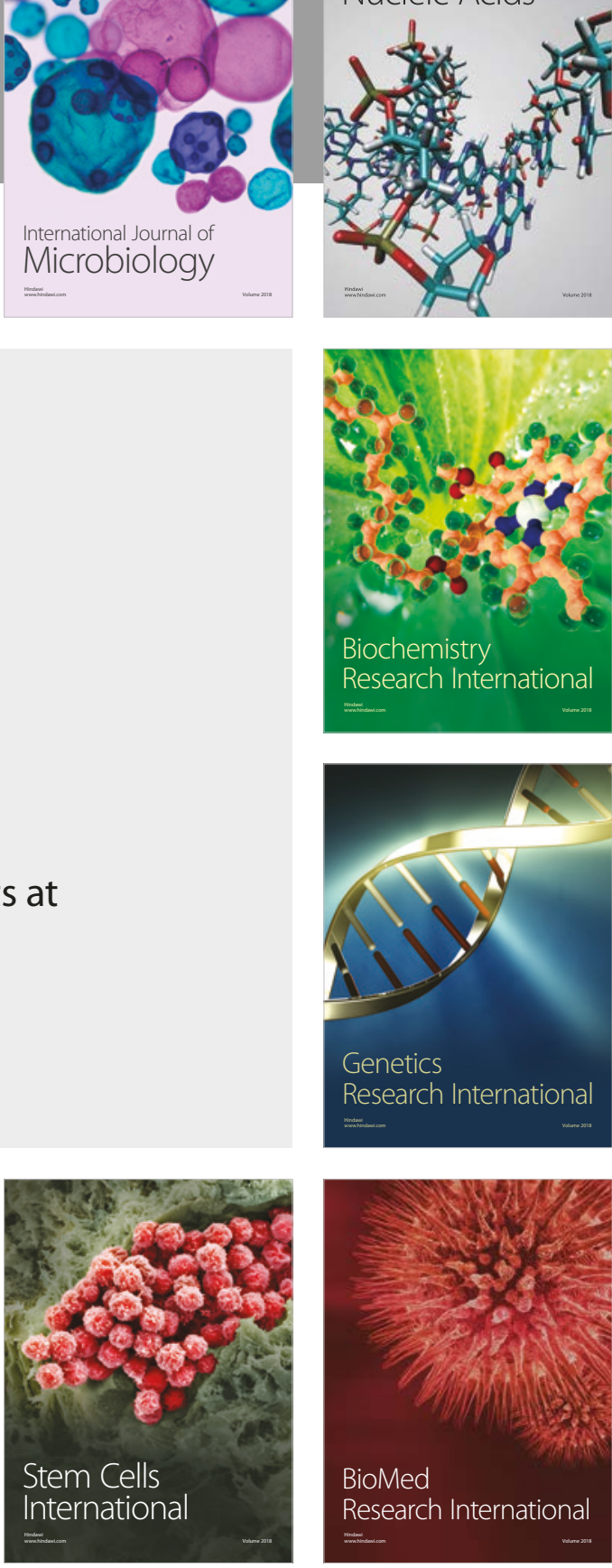
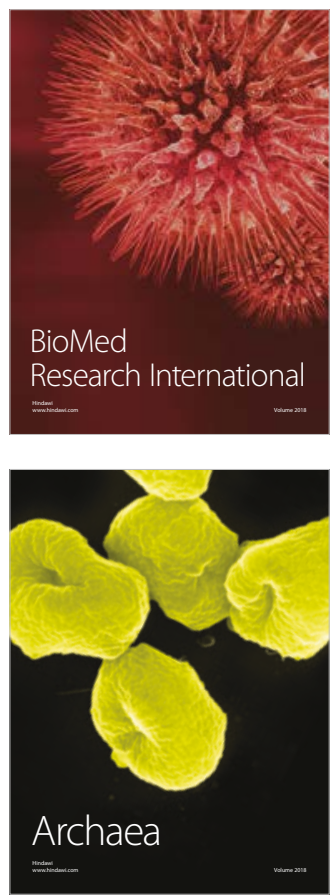